\title{
Manufacturing of a 3d Finned Tube for Enhanced Boiling and Condensation Using Rolling-cutting- extruding Composite Forming
}

\section{Xiaofang Huang}

South China University of Technology School of Mechanical and Automotive Engineering Hanping Chen

South China University of Technology School of Mechanical and Automotive Engineering

Zhen-ping Wan ( $\square$ zhpwan@scut.edu.cn )

South China University of Technology

\section{Longsheng Lu}

South China University of Technology School of Mechanical and Automotive Engineering

\section{Hongguan Zhu}

Guangdong Longfeng Precision Copper Tube Co.,Ltd, Zhuhai 519000,PR China

\section{Yong Tang}

South China University of Technology School of Mechanical and Automotive Engineering

\section{Research Article}

Keywords: Rolling, 3D finned tube, enhanced boiling/condensation, rolling-cutting tool

Posted Date: February 12th, 2021

DOl: https://doi.org/10.21203/rs.3.rs-216125/v1

License: (1) This work is licensed under a Creative Commons Attribution 4.0 International License. Read Full License

Version of Record: A version of this preprint was published at The International Journal of Advanced Manufacturing Technology on August 13th, 2021. See the published version at https://doi.org/10.1007/s00170-021-07801-0. 


\title{
Manufacturing of a 3D finned tube for enhanced boiling and condensation using rolling-cutting-extruding composite forming
}

\author{
Xiaofang Huang ${ }^{1}$, Hanping $\mathrm{Chen}^{1}$, Zhenping Wan ${ }^{1, *}$, Longsheng $\mathrm{Lu}^{1}$, Hongguan $\mathrm{Zhu}^{2}$, Yong Tang ${ }^{1}$ \\ ${ }^{1}$ School of Mechanical and Automotive Engineering, South China University of Technology, Guangzhou \\ 510640, PR China \\ ${ }^{2}$ Guangdong Longfeng Precision Copper Tube Co., Ltd, Zhuhai 519000, PR China \\ *Corresponding author, E-mail: zhpwan@scut.edu.cn
}

\begin{abstract}
D finned tube is a high efficient enhanced heat transfer element and its manufacturing has always been the focus of research's attention. It is a challenging job to manufacture a 3D finned tube that can enhance both boiling and condensation because the enhanced boiling structure is completely different from the enhanced condensation structure due to different heat transfer enhancement mechanisms. An innovative rolling-cuttingextruding composite forming method is developed to realize the manufacture of a staggered stepped lattice finned tube (SLFT) with helical fins, two layers of staggered stepped lattice fins and inner helical threads, which can enhance boiling as well as condensation heat transfer. The three skewed rolling-cutting tools specially designed are uniformly distributed around the base tube and the kinematics conditions of rolling-cutting-extruding process is analyzed. The relative plunge depth of a rolling blade can't exceed a certain limit value and the feeding angle has to be equal to the helix angle of outer helical fin. According to the kinematic conditions, the parameters of the rolling-cutting tool are selected and processing experiments of the SLFT are conducted.
\end{abstract}

Keywords: Rolling; 3D finned tube; enhanced boiling/condensation; rolling-cutting tool

\section{Acknowledgments}

This work is sponsored by the Key Research and Development Project of Guangdong Province (2020B090926004) and Science and Technology Planning Project of Guangdong Province, China (2015B020238004) 


\section{Nomenclature}

\begin{tabular}{|c|c|c|c|}
\hline$p$ & Pitch of helical fin (mm) & $\theta$ & Helix angle $\left(^{\circ}\right)$ \\
\hline$h$ & Height of helical fin (mm) & $\alpha$ & Feeding angle $\left(^{\circ}\right)$ \\
\hline$w$ & Width of lattice fin (mm) & $\mu$ & Friction coefficient \\
\hline$\omega_{1}$ & Angular speed of rolling cutter ( $\mathrm{rad} / \mathrm{min})$ & $\omega_{2}$ & Angular speed of tube ( $\mathrm{rad} / \mathrm{min})$ \\
\hline$D$ & Diameter of a rolling blade $(\mathrm{mm})$ & $n$ & Rolling speed (r/min) \\
\hline$d$ & Diameter of tube (mm) & $P$ & Rolling force $(\mathrm{N})$ \\
\hline$Z$ & Plunge depth of a rolling blade (mm) & $F$ & Tangential friction force $(\mathrm{N})$ \\
\hline$t$ & Thickness of rolling cutter (mm) & $N$ & Number of teeth of rolling cutter \\
\hline$a$ & Arm of tangential force (mm) & $b$ & Arm of Rolling force (mm) \\
\hline$V_{x}$ & Axial speed of a point on a rolling blade & $V_{\mathrm{t}}$ & Axial speed of tube \\
\hline$\Delta h$ & Height difference of two stepped fins (mm) & $\varphi$ & Center angle $\left(^{\circ}\right)$ \\
\hline$R$ & Radius of the rolling-cutting tool (mm) & $r$ & External radius of the tube \\
\hline$\Delta H$ & Height difference in radius of tooth and flat & $(\mathrm{mm})$ & \\
\hline
\end{tabular}

\section{Introduction}

The heat exchange tube is the core component of a shell and tube heat exchanger, and the enhanced boiling and condensation heat exchange tubes can promote the performance of an evaporator and condenser greatly [1,2]. In recent years, with the increasing demand of high efficient, light-weight and compact requirements, the new generation heat exchanger, such as heat pump, is developing towards integration of refrigerating and heating. It demands that heat exchange tubes not only have excellent enhanced boiling heat transfer performance, but also possess brilliant enhanced condensation heat transfer performance. Hence, it puts forward to the heat exchange tubes and their manufacture a big challenge because the enhanced boiling structure is completely different from the enhanced condensation structure due to different heat transfer enhancement mechanisms. Encouragingly, a novel three-dimensional (3D) finned tubes - staggered stepped lattice finned tube (SLFT) with outer helical fins, two layers of staggered stepped fins and inner helical threads is presented and has been proven to be able to 
enhance both boiling and condensation heat transfer greatly [3]. However, there is not a lowcost, efficient and effective manufacturing method to produce the SLFT although the manufacture of enhanced heat exchange tubes for boiling and condensation heat transfer has always caught researcher's interest.

So far, many researchers have gravitated towards the manufacture of enhanced boiling and condensation tubes. The surface porous tube and finned tube are the typical representatives of enhanced boiling tubes [1]. The finned tubes are mainly of dimple tube, micro-fin tube, integral fin tube, dimple-grooved tube [4]. The main manufacturing methods of these enhanced tubes are coating and sintering [5], flame spraying [6], machining [7] and electrochemical corrosion methods [8]. Among these methods, the most commonly used method is the sintering, followed by the flame spraying because the surface porous structures produced by the sintering and flame spraying have very excellent enhanced boiling properties. The third method used widely is machining, e.g. ploughing by which the finned structure with rough surface can be produced [7]. The electrochemical corrosion methods are mainly used to manufacture the enhanced boiling tube for some special applications [8]. In addition, the high-speed spinning is a machining method for internally-grooved tube [9], aiming at boiling enhancement inside the tube. To promote productivity and reduce cost, Kuboki et al. [10] developed a special extruding method to manufacture the tube with helical inner fins.

Edge-shaped finned tube [11], micro-fin tube [12], turbo C tube, herringbone tube, V-type and W-type micro-finned tubes, dimple-grooved tube [13] and 3-D finned tube [14] are the main types of enhanced condensation heat exchange tubes. The manufacturing methods of these enhanced condensation tubes mainly include extruding [15], casting [16], welding $[17,18]$, rolling [19, 20], extrusion-plough [21] chopping-extrusion [22] and rolling-wedging/extruding methods [23]. Among them, the extruding method is a conventional and common manufacturing method for condenser tube, but it is very difficult to produce complex fins [15]. The casing [16] and welding methods $[17,18]$ are used to manufacture non-integral finned tubes and complex special-shaped tubes. However, the enhanced tubes produced by casting and welding have a large contact thermal resistance though the laser welding can improve the 
quality of welded joints [18]. The rolling-wedging/extruding method is widely used to manufacturing enhanced condensation tube with three-dimensional integral fins. Recently, to promote fin efficiency, some novel fins, such as the circular plain fin, circular integrated pin fin and serrated integrated pin fin are fabricated by the selective laser melting [24]. The selective laser melting can fabricate complex fins, but its productivity and manufacturing cost can't meet the requirements of producers.

Obviously, the above manufacturing methods can't be applied to the SLFT production at low cost and high efficiency. Moreover, the enhanced boiling and condensation tubes manufactured by the above methods can only be applied to a single boiling or condensation condition. Namely, if an enhanced boiling tube is used to condensation condition, its heat transfer performance will drop dramatically, and vice versa. Therefore, how to manufacture this kind of heat exchange tube which can enhance boiling as well as condensation, e.g. SLFT is a severe challenging job and has become an obstacle to developing the new heat exchanger integrated refrigerating and heating.

This work proposes a novel manufacturing method-rolling-cutting-extruding composite forming based on the three-roll skewed rolling to manufacture the new 3D finned tube-SLFT. To achieve the efficient and collaborative manufacturing of outer and inner fins of the SLFT, the combined rolling-cutting tool is designed and the kinematic conditions of rolling-cuttingextruding process is investigated. The influence of processing parameters on the morphologies and geometric dimensions of the outer fin structure are investigated.

\section{Developing of rolling-cutting-extruding composite forming}

\subsection{Structure characteristics of the SLFT}

The schematic diagram of the SLFT is shown in Fig. 1. The two-dimensional (2D) helical fin is the outer fin structure foundation. The pitch and size of the 2D helical fins are small and the groove bottom is concave, which meets the requirements of enhancing boiling and condensation at the same time. Two layers of staggered lattice fins with a certain height difference are distributed on both side walls of the helical fins. Thus, the groove is divided into upper and lower parts by the two layers of staggered fins and two porous layers form along the 
circumferential direction. Under the separation of the stepped fins, the lower part of the fin slot becomes a semi-closed chamber and the holes formed between the two stepped fins connect the upper and lower slots. The chambers communicate with each other to form a helical channel. In addition, trapezoidal threaded fins are distributed on the inner surface of the SLFT. The geometric parameters of the SLFT can be characterized by the pitch $p$, height of 2D helical fin $h$, fin width $w$ and height difference of the two stepped fins $\Delta h$.
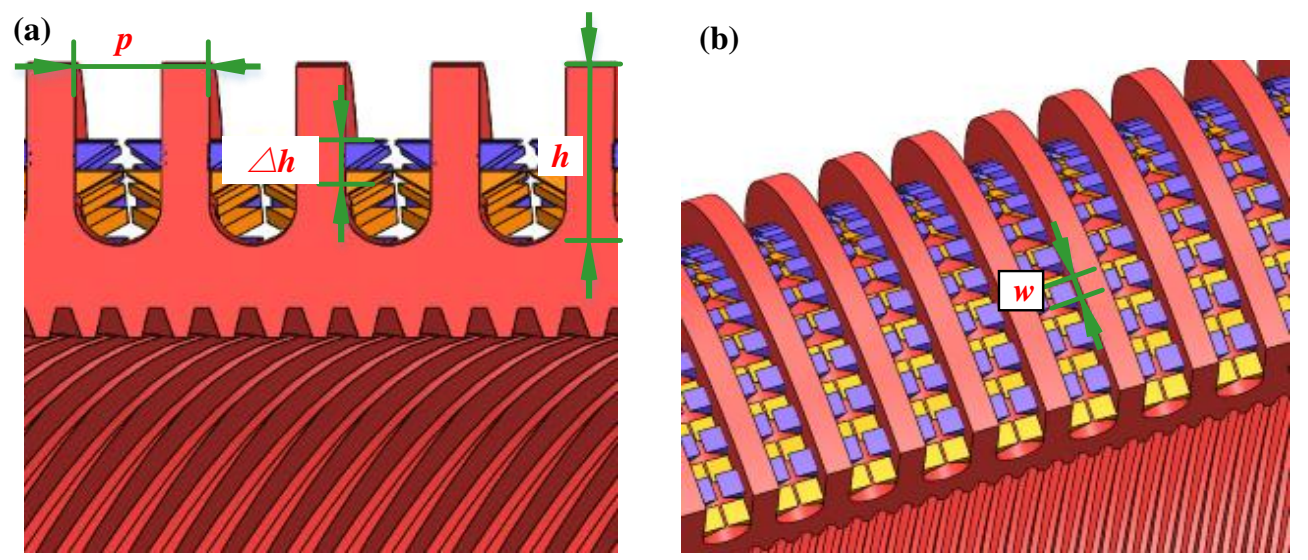

Fig. 1 Schematic diagram of the SLFT: (a) longitudinal section view (b) top view

\subsection{Manufacturing of 3D staggered stepped lattice fins}

\section{(1) Multi-stage rolling of outer 2D helical fins}

Since the outer fin structure foundation is the 2D helical fin, the manufacturing method of the SLFT should be based on the rolling process which is an efficient and stable method for producing outer helical fin. In order to obtain the $2 \mathrm{D}$ helical fins with a large aspect ratio and high integrity, a multi-stage rolling is adopted, as shown in Fig. 2. Thus, the 2D helical fins can be rolled out progressively.

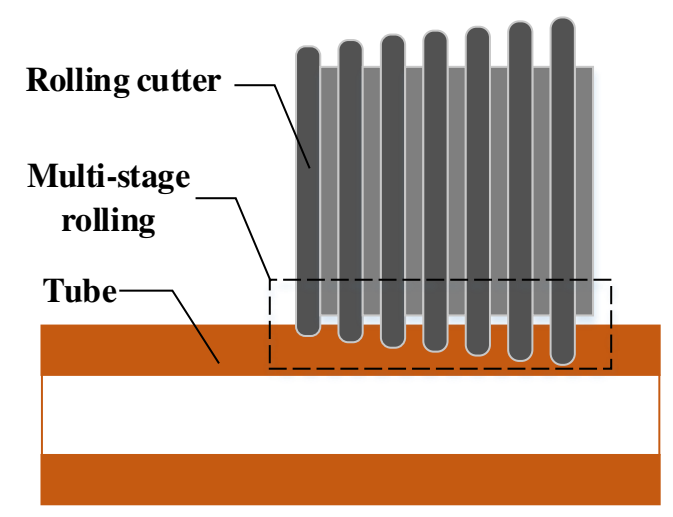

Fig. 2 Multi-stage rolling of 2D helical fins 


\section{(2) Rolling-cutting of staggered stepped lattice fins}

After the helical fins formed, the lower layer of stepped fins is machined on the side walls of the adjacent helical fins by a tooth cutter as shown in Fig. 3(a). The teeth of the tooth cutter are intermittently distributed. Then, a flat cutter is used to machine the upper layer of stepped fins as shown in Fig. 3(b). Thus, the two staggered layers of fins are machined out on the side wall of the 2D helical fins.
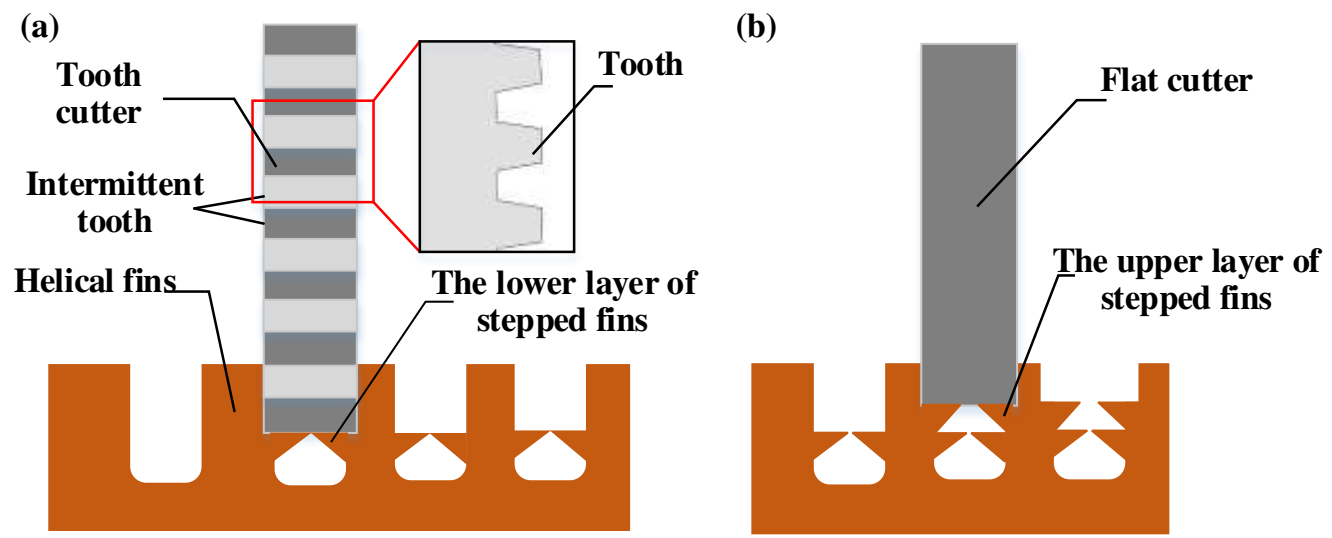

Fig. 3 Forming method of stepped fins: (a) the first layer of stepped fin; (b) the second layer of stepped fin

\section{(3) Design of rolling-cutting tool}

Based on the multi-stage rolling of 2D helical fins and the rolling-cutting of staggered stepped lattice fins, the rolling-cutting forming tool of the 3D stepped lattice fins is designed as shown in Fig. 4. The forming tool is consisted of rolling blades, shims, tooth cutter and flat cutter. To assure the 3D staggered stepped lattice fins forming, the diameter of the rolling blades increases progressively.

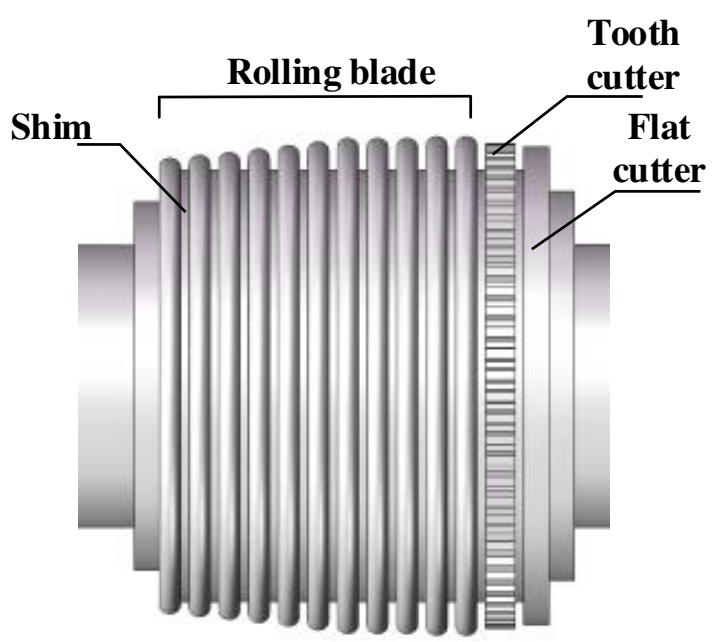

Fig. 4 Schematic diagram of combined rolling-cutting tool 


\subsection{Collaborative manufacturing of 3D outer fin and inner helical thread}

From the above analysis, the forming process of 3D outer fins can be divided into two stages: One is the rolling of 2D helical fins, the other is the rolling-cutting of the $3 \mathrm{D}$ stepped lattice fins. During the 3D outer fins forming, the base tube is subjected to a large rolling force. So, adding a threaded mandrel to the inside of the tube (as shown in Fig. 5(a)) can achieve the extruding forming of inner helical threads as well as bearing rolling force and preventing the rolled tube from collapsing. Fig. 5(b) presents the configuration of the threaded mandrel. The relative rotation between the threaded mandrel and the base tube is demanded in the process of extruding forming of inner helical threads. In this work, the threaded mandrel remains fixed and the base tube rotates.
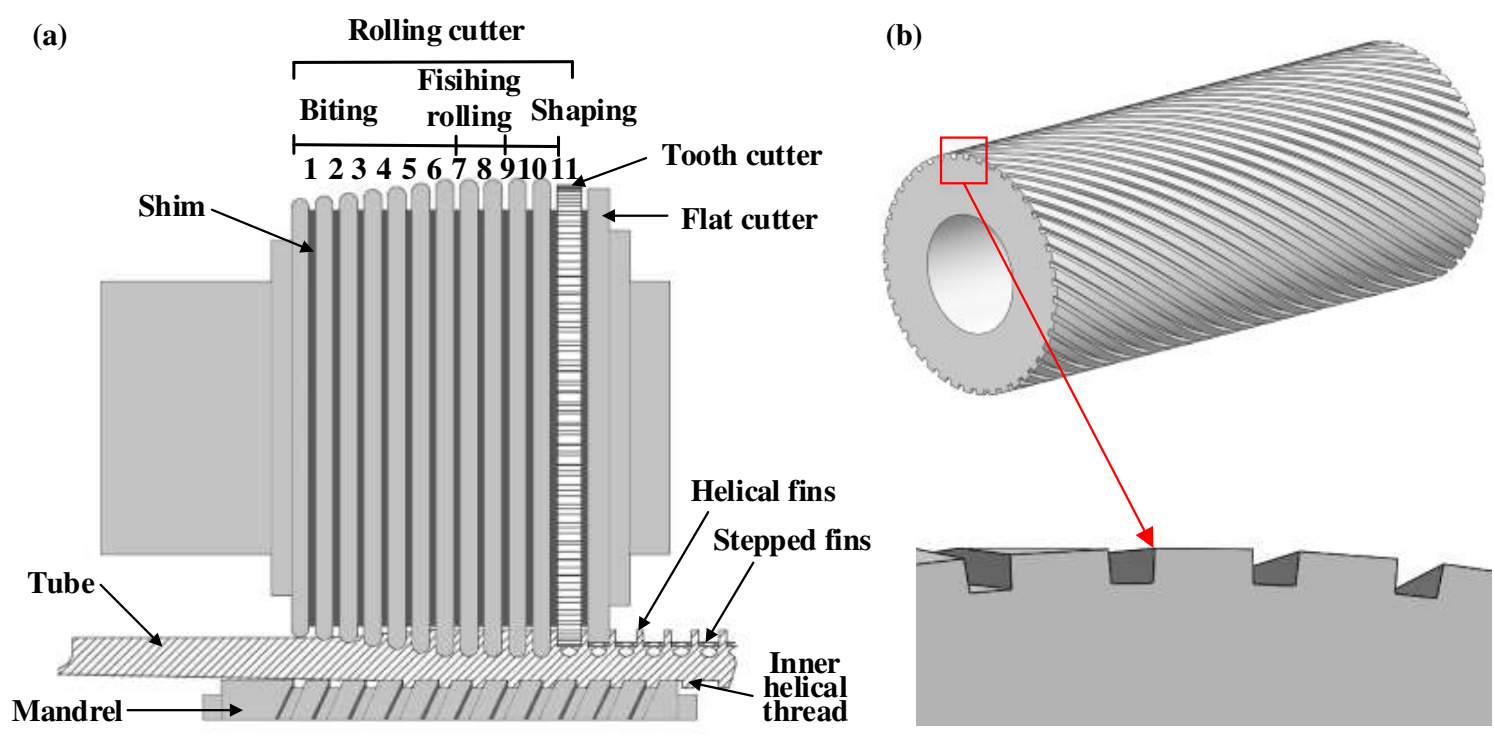

Fig. 5 (a) schematic diagram of cooperative manufacturing of SLFT (b) configuration of the threaded

mandrel

Therefore, the progressive forming of 2D outer helical fins can be characterized by three periodic repeated processes: biting, finishing rolling and shaping.

(1) Biting

The rotating rolling blades acts on the tube surface and bites the tube, thus causing the tube rotating and moving forward axially. As processing proceeds, the helical fins forming gradually due to the progressive increase of the rolling blade diameter. At the same time, the inner wall of the tube shrinks and comes into contact with the threaded mandrel. In this stage, the height of helical fins increases progressively due to restriction of material flowing in the 
axial direction.

(2) Finishing rolling

After the action of the first several rolling blades, the outer and inner helical fins have been initially formed. To achieve the finishing rolling, the outer diameter of the next two rolling blades remains unchanged at this stage. Under the action of the finishing rolling, the fins basically form and the morphological qualities are improved because the elastic recovery of the material is reduced.

(3) Shaping

The helical fins are trimmed by the following shaping blades, and the morphological of the fins has been further improved. Thus, the outer helical fins form finally. Also, the inner helical fins form simultaneously under the combined extruding action of the rolling cutter and threaded mandrel.

After the outer helical fins form fully, the tooth cutter and flat cutter act on the side walls of two adjacent helical fins successively as shown in Fig. 5(a). Then two layers of staggered stepped lattice fins are machined out under the cutting and extruding action of the tooth and flat cutter. A groove is divided into upper and lower parts by the two layers of staggered stepped fins and porous structure forms. The lower part of the fin slot forms an evaporation chamber under the sealing effect of the stepped fins and there are lots of pores between the upper and lower part of fin slot.

\section{Kinematic conditions of rolling-cutting-extruding process}

As above-mentioned, to realize continuous manufacturing of the SLFT, the relative rotational and axial motions are demanded between the rolling-cutting tool and base tube. To achieve the goal, three skewed rolling-cutting tools are used and uniformly distributed around the base tube as shown in Fig. 6(a). There is a skewing angle called feeding angle $\alpha$ between the two axes of rolling-cutting tool and tube. Hence, the speed of a point on a rolling blade can be resolved into axial speed $V_{\mathrm{x}}$ and tangential speed $V_{\mathrm{y}}$ as indicated in Fig. 6(b). During the 3D outer fins forming, the base tube are rolled by the skewed rolling-cutting tools. In this case, the 
frictional force generated between the rolling-cutting tool and base tube can be decomposed into tangential force and axial force. Consequently, the base tube rotates and moves axially driven by the tangential and axial force respectively. In addition, the three rolling-cutting tools are staggered by one-third pitch along the axis.
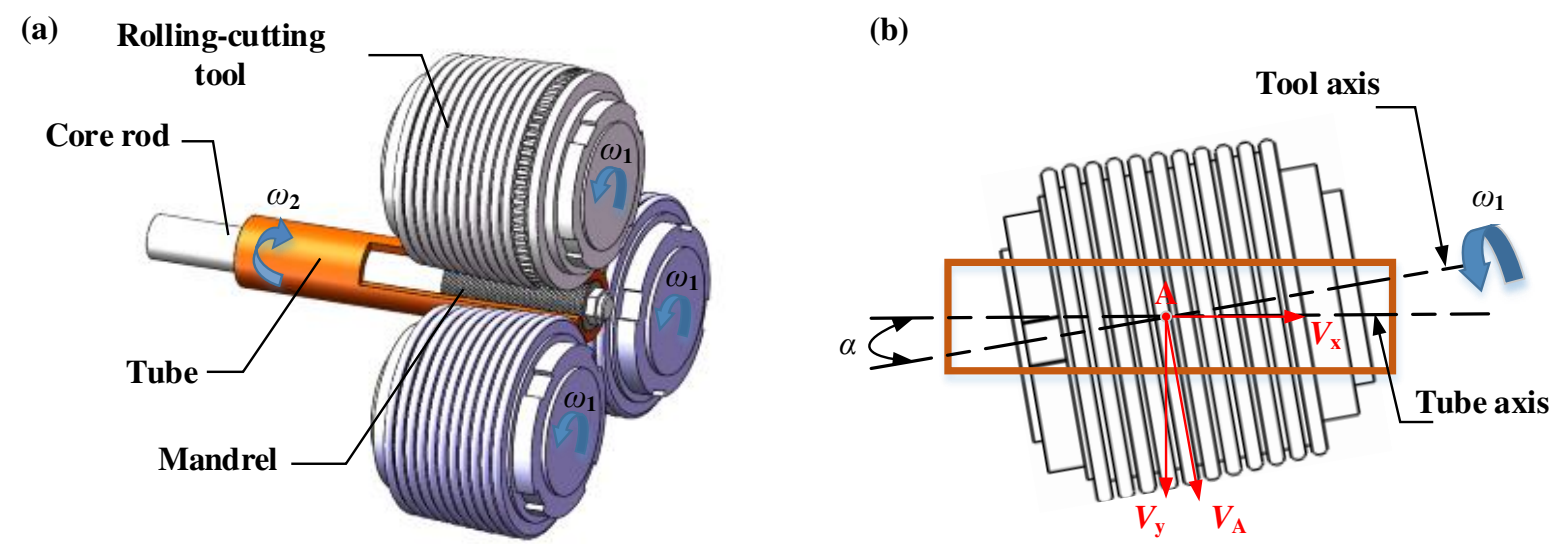

Fig. 6 (a) Rolling-cutting-extruding forming of SLFT, (b) Schematic diagram of three-roller skew-rolling

\subsection{Rotational motion condition}

To make the tube rotate and move forward axially at the same time, the conditions of rotation and axial movement must be met. The forces imposed on the tube during the rollingcutting-extruding process are shown in Fig. 7. The condition of rotational motion is that the torque of friction force $F$ is greater than the torque of pressure $P$, named as:

$$
\mathrm{Fa}>\mathrm{Pb}
$$

where $a$ and $b$ are the force arm of the friction force and pressure against the axis of the tube.

The relationship between the friction force $F$ and the pressure $P$ is:

$$
F=\mu P
$$

where $\mu$ is the friction coefficient between tube and rolling-cutting tool. From the analysis of forces imposed on the tube shown in Fig. 7, the calculation of the force arm $a$ and $b$ is as follows:

$$
\begin{gathered}
a=\left[r-\left(\frac{R}{\cos \varphi}-R\right)\right] \cos \frac{\varphi}{2} \\
b=(R+r) \sin \frac{\varphi}{2}
\end{gathered}
$$

where $R$ is the radius of a rolling blade, $r$ is the external radius of the tube, and $\varphi$ is the center angle corresponding to the arc length between the rolling-cutting tool and the tube. In addition, 
the following formula can be obtained from geometric relations:

$$
\cos \varphi=1-\frac{2\left(d Z+Z^{2}\right)}{D(D+d)}
$$

where $Z$ is the plunge depth of a rolling blade of the rolling-cutting tool, $d$ the outer diameter of the tube. Therefore, the condition for stable rotation of the tube is as follows:

$$
\mu^{2} \geq\left(1+\frac{d}{D}\right)\left(\frac{Z}{d}\right)
$$

It can be seen that the friction coefficient $\mu$ has the greatest influence on the rotation conditions of skew-rolling. In cold rolling, the friction coefficient is a constant value. Hence, the relative plunge depth of a rolling blade $[Z / d]$ has a maximum value as following:

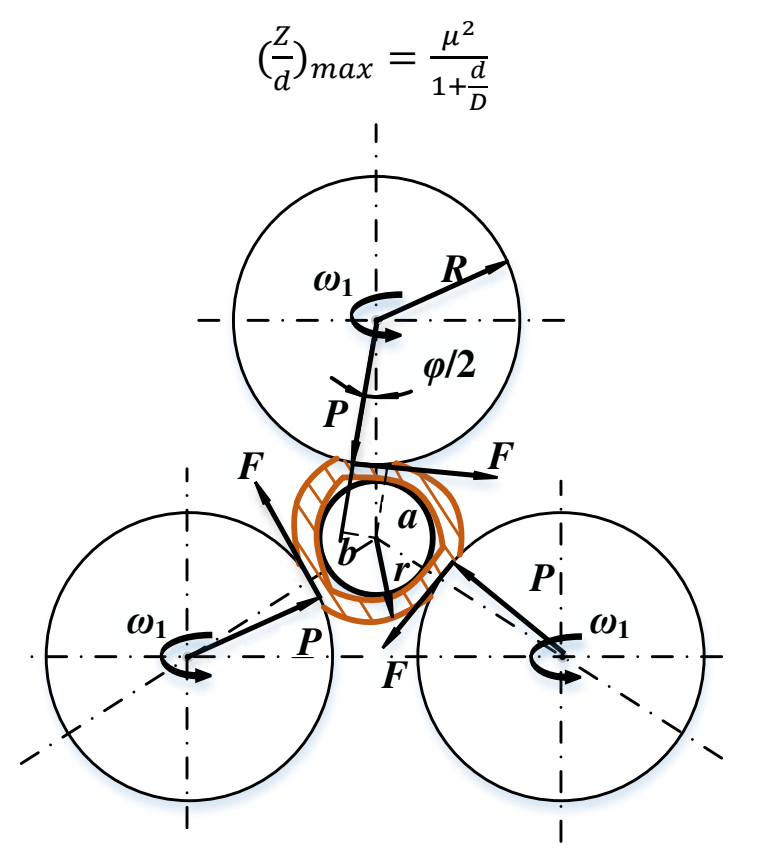

Fig. 7 Schematic diagram of forces imposed on the tube

It can also be known that the smaller the ratio of the diameter of tube to a rolling blade, the easier is it for the tube to rotate. Generally, the value of $d / D$ is $1 / 2 \sim 1 / 6$ in the skew-rolling process. Hence, the relative plunge depth of a rolling blade of the rolling-cutting tool should not exceed the maximum permissible value.

\subsection{Axial motion condition}

Moreover, the tube also needs to follow the principle of axial movement. When the tube advances one pitch $(p)$ in the axial direction, it exactly rotates one revolution. In this way, the axial velocity $\left(V_{\mathrm{t}}\right)$ of the tube is: 


$$
V_{t}=\frac{p \omega_{2}}{2 \pi}=\frac{p R_{A}}{2 \pi r_{A}} \omega_{1} \cos \alpha
$$

When $V_{\mathrm{x}}$ is greater than or less than $V_{\mathrm{t}}$, the tube cannot pass through the rolling zone smoothly, which will cause damage to the tube and severe wear of the rolling-cutting tool. Only when $V_{\mathrm{x}}$ is equal to $V_{\mathrm{t}}$, the tube can be steadily rolled. The helical rise angle $\theta$ of the finned tube is:

$$
\theta=\arctan \frac{p}{2 \pi r_{A}}
$$

Thus, it can be concluded that the axial movement condition of the tube is:

$$
\alpha=\theta
$$

That is, the feeding angle of three-roller is equal to the helical rise angle of the finned tube.

\section{Experimental results}

\subsection{Experimental conditions}

Experiments are conducted on the self-developed three-roll skewed rolling mill. In the experiments, the workpiece is red copper tube with outer diameter of $19 \mathrm{~mm}$, wall thickness of $1.15 \mathrm{~mm}$, and length of $2000 \mathrm{~mm}$. The materials of rolling-cutting tool is T8MnA. The friction coefficient $\mu$ obtained from experiments is 0.12 . Thus, it can be calculated from the Eq. (7) that the plunge depth of every rolling blade $\mathrm{Z}$ cannot exceed $0.21 \mathrm{~mm}$. Hence, $\mathrm{Z}$ is selected as 0.15 $\mathrm{mm}$ to achieve stable processing of helical fins. According to the actual needs, the outer helical fin height and helix angle are determined as $1 \mathrm{~mm}$ and $42^{\prime}$ respectively. Therefore, in the biting stage, seven rolling blades are needed and accordingly, the total plunge depth is $0.9 \mathrm{~mm}$. In the rolling stage, the outer diameter of the two rolling cutters keep fixed and is equal to the diameter of the seventh rolling blade. In the shaping stage, the plunge depth is set as $0.1 \mathrm{~mm}$ and two rolling blades are used. In the rolling-cutting-extruding process, the feed angle is set as $42^{\prime}$ and three rolling speeds of $173 \mathrm{r} / \mathrm{min}, 235 \mathrm{r} / \mathrm{min}$, and $337 \mathrm{r} / \mathrm{min}$ are used for the combined rollingcutting tool.

\subsection{Appearance and characteristics of a manufactured SLFT}

Fig. 8 presents the appearance and characteristics of the SLFT obtained at rolling speed of 173 r/min. From Fig. 8, the outer fins are consisted of 2D helical fin, two layers of intermittent and staggered fin. The 2D helical fin is the foundation of outer 3D fin and the two layers of staggered fin protrude on the side wall of $2 \mathrm{D}$ helical fins. The staggered stepped lattice fins 
have sharp edges and a rough surface. The lower fins and grooves of helical fins contribute to lower semi-enclosed slots along the circumference. The upper fins, lower fins and side walls of helical fins compose upper slots. From Fig. 8(b), there are also many porous structures along the radial direction of the copper tube. Besides, the inner helical threads with trapezoidal cross section are rolled out as shown in Fig. 8(c). Therefore, the SLFT can be manufactured perfectly by rolling-cutting-extruding composite forming.

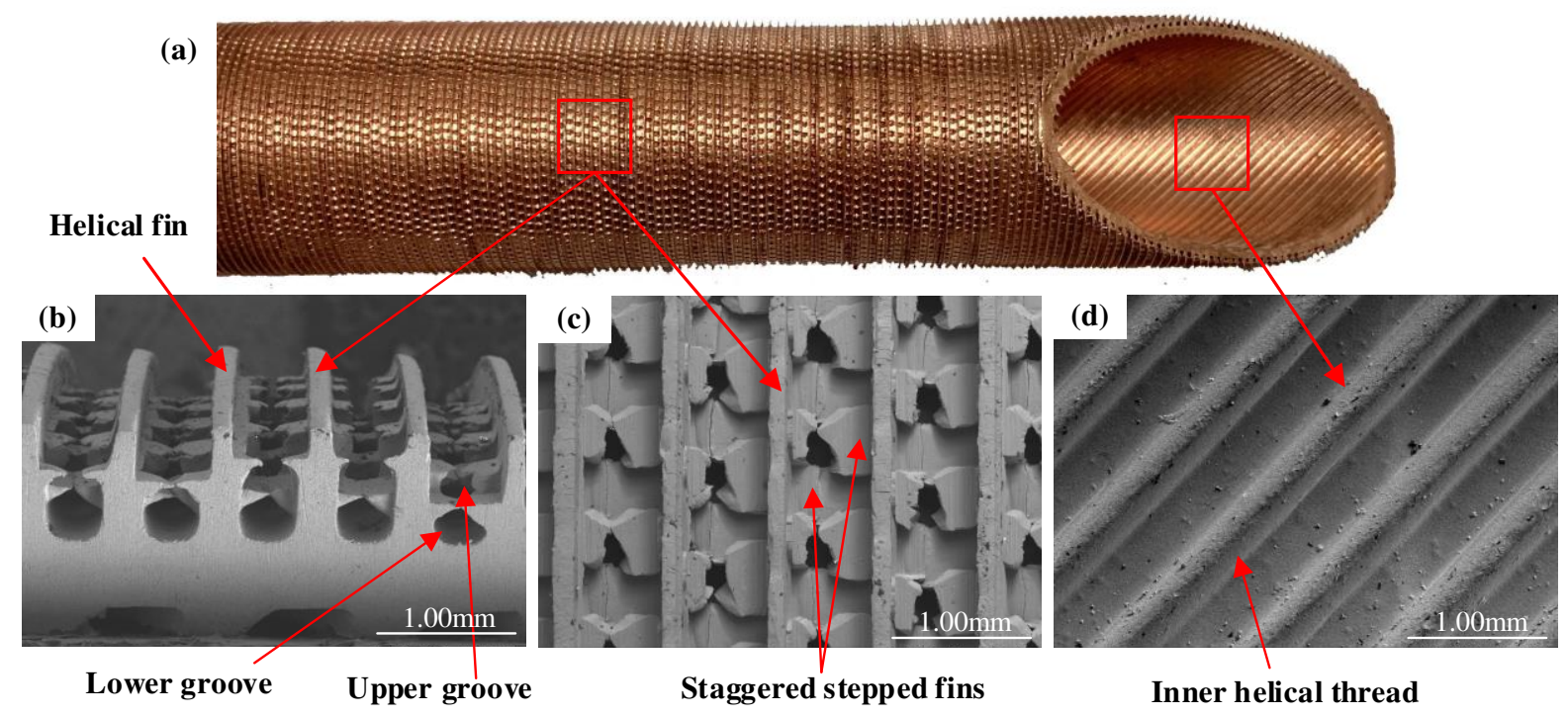

Fig. 8 Appearance and characteristics of the SLFT: (a) appearance, (b) outer helical fins and (c) stepped lattice fins, (d) inner helical threads

\subsection{Influence of technical parameters on forming of SLFT}

\subsubsection{Influence of rolling speed}

Fig. 9 shows the SEM images of the SLFT machined at the three different rolling speeds. When the rolling speed is $337 \mathrm{r} / \mathrm{min}$, the $2 \mathrm{D}$ helical fins of the SLFT is well formed, but the stepped lattice fins have serious defects as shown in Figs. 9(a-b). The reason is that the rolling speed of $337 \mathrm{r} / \mathrm{min}$ makes the tube rotate at $1180 \mathrm{r} / \mathrm{min}$. In this case, the fins formed by the previous tooth of the tooth cutter are easy to be cut by the next tooth, leading to defects in the stepped fins. In addition, when the tube rotates at so high speed, a severe vibration occurs, resulting in deviations of the tooth cutter and flat cutter during the rolling-cutting process. 


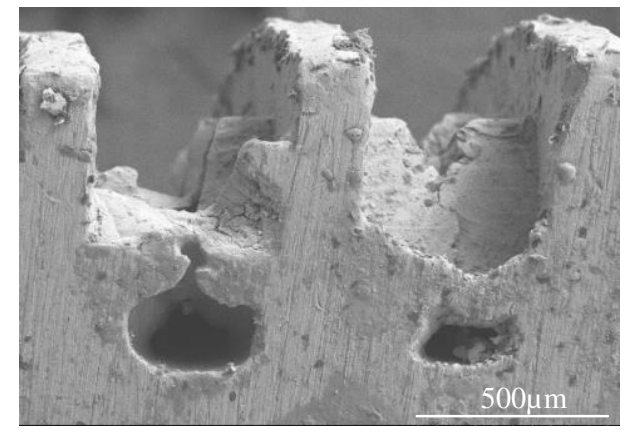

(a) Longitudinal section view

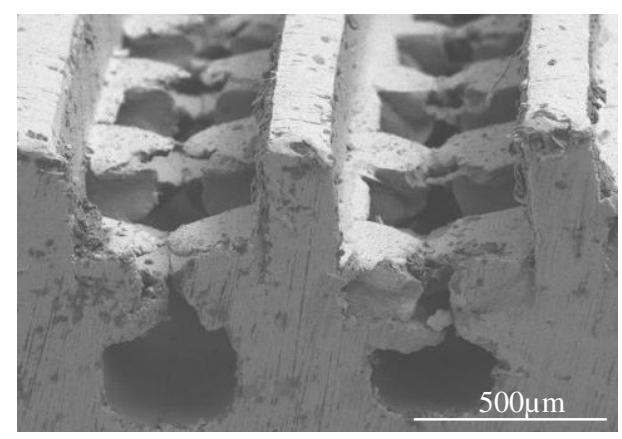

(c) Longitudinal section view

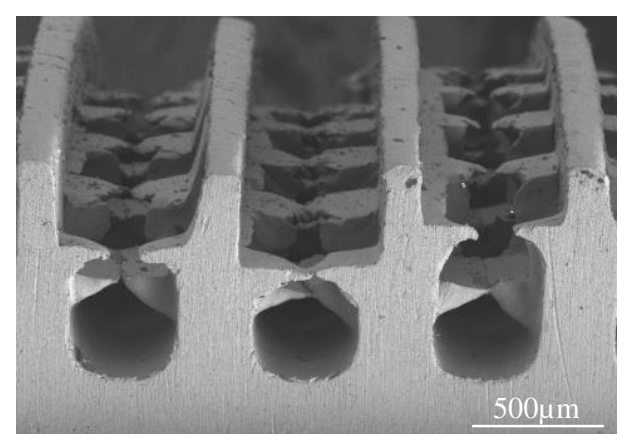

(e) Longitudinal section view

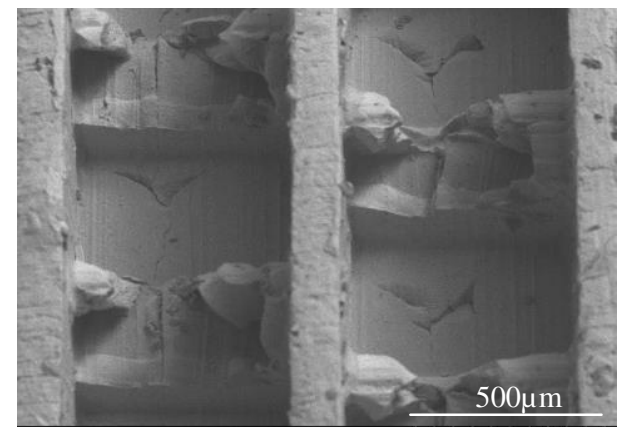

(b)Top view

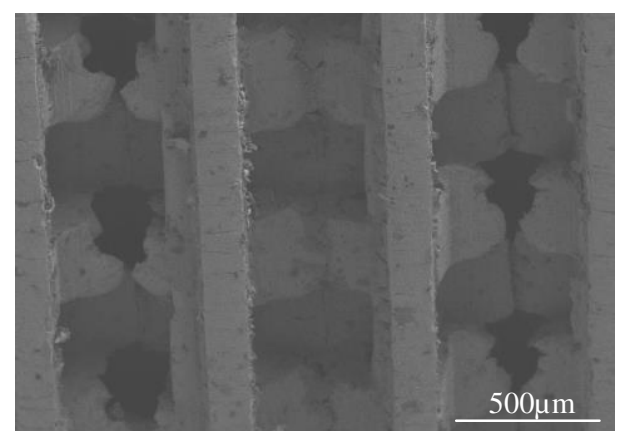

(d)Top view

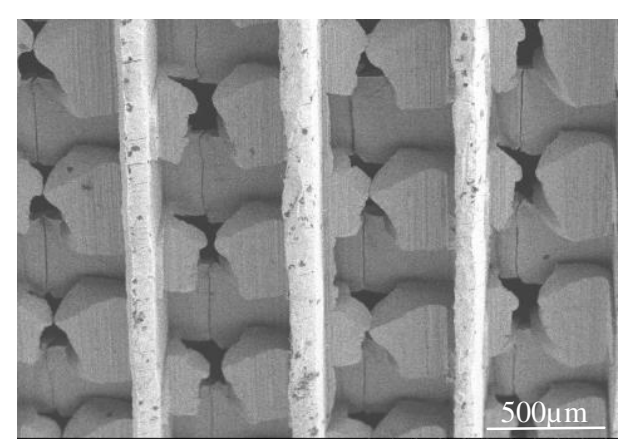

(f)Top view

Fig. 9 Morphologies of the SLFT machined at rolling speed of: (a-b) 337r/min, (c-d) 235 r/min, (e-f)

\section{$173 \mathrm{r} / \mathrm{min}$}

When the rolling speed drops to $235 \mathrm{r} / \mathrm{min}$, the vibration occurred decreases greatly, which reduces the deviation of the tooth cutter and flat cutter. Hence, the integrity of the two stepped lattice fins are improved as shown in Fig. 9(c-d). But, it is not perfect yet. When the rolling speed is reduced to $173 \mathrm{r} / \mathrm{min}$, the rolling process is very smooth. The forming quality of helical fins and the two stepped lattice fins are further improved and there are few defects as shown in Fig. 9(e-f). Therefore, to achieve the SLFT forming smoothly, the low rolling speed should be used. 


\subsubsection{Influence of tool parameters}

When the speed of the rolling-cutting tool is $173 \mathrm{r} / \mathrm{min}$ and the thickness of the shim is $0.254 \mathrm{~mm}$, the changes of the pitch and height of the 2D helical fins with the thickness of the rolling blade are shown in Fig. 10. Obviously, Fig. 10(a) shows the pitch of the helical fin increases with the increase of rolling blade thickness. In addition, it can be seen from Fig. 10(b) that the height of the helical fin increases with the increase of rolling blade thickness. However, the rate of rise decreases gradually. The reason may be that with the increase of height of helical fins, the diameter of helical fins increases and more metal volume is needed to meet the increase of height.
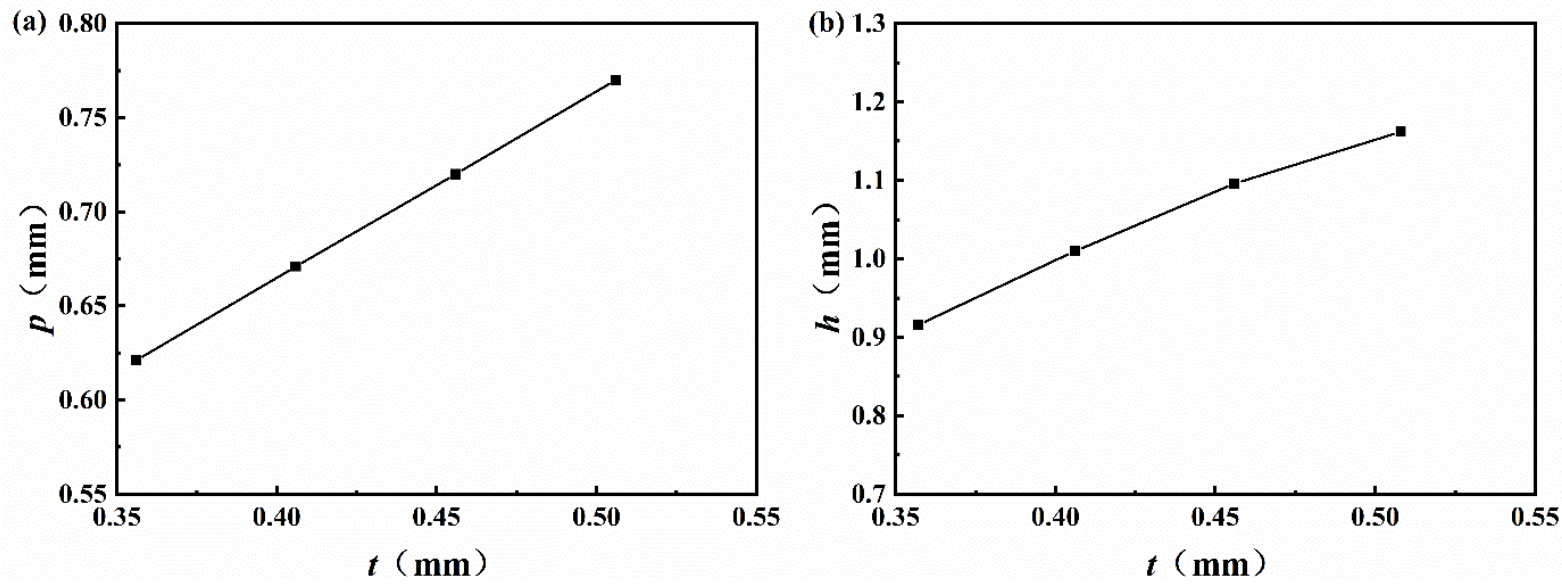

Fig. 10 Pitch and height of 2D helical fins vs. the thickness of rolling blade: (a) pitch, (b) height difference of two layers of stepped fins with the difference in radius of the tooth cutter and flat cutter

Fig. 11(a) shows the widths of the upper lattice fin vary with the number of teeth of the tooth cutter when the outer diameter of the tooth cutter is constant. The fin width decreases with the increase of the number of teeth. It is because the tooth width of a tooth cutter decreases as the number of teeth increases. What's more, Fig. 11(b) shows the varied trend of the height difference $\Delta h$ of two layers of stepped fins with the height difference $\Delta H$ in radius of the tooth cutter and flat cutter. The height difference of the stepped fins increases with the increase of the height difference between the tooth cutter and flat cutter in radial direction. However, the $\Delta h$ is smaller than the $\Delta H$. The reason is due to the elastic recovery of the stepped fins extruded. 

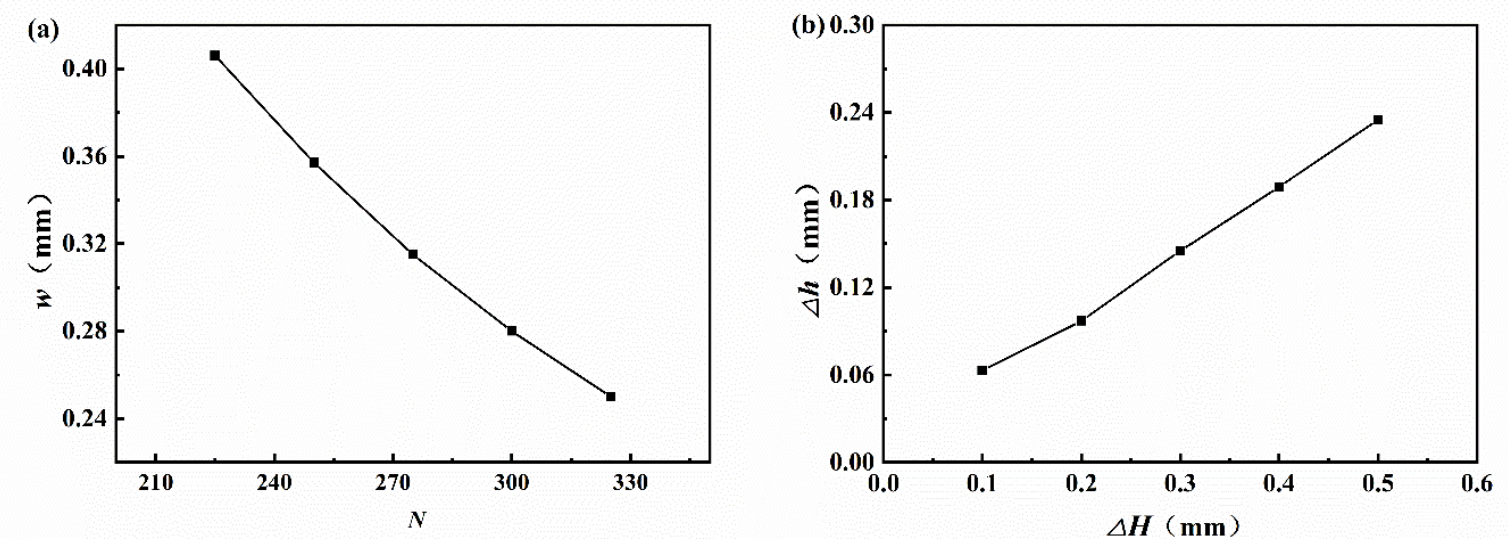

Fig. 11 Variation trend of: (a) fin width varies with the number of teeth of the tooth cutter, (b) height

\section{Conclusion}

(1) The rolling-cutting-extruding composite forming method can be used to realize efficient and cooperative manufacturing of an enhanced boiling/condensation three-dimensional finned tube (SLFT) with outer helical fins, two layers of staggered stepped fins and inner helical threads.

(2) The forming process of the SLFT is divided into two of stages: 2D helical fins rolling forming and staggered stepped fins cutting/extruding forming. The forming process of the $2 \mathrm{D}$ helical fins includes biting, finishing rolling and shaping process, and the inner threaded fins are also formed at this stage. During the staggered lattice fins forming, the $2 \mathrm{D}$ helical fins are successively cut and extruded by the tooth cutter and flat cutter to form two layers of stepped fins with a height difference.

(3) To meet the rotational and axial movement conditions during the SLFT rolling-cuttingextruding forming, the plunge depth of a rolling blade cannot exceed a limit value and the feeding angle need to be equal to the helical angle of the 2D fin. Excessive rolling speed is unfavorable for manufacturing of the SLFT.

\section{Declarations}

Authors' contributions Xiaofang Huang performed the data analyses and wrote the manuscript; Hanping Chen performed the experiment; Zhenping Wan contributed significantly to analysis and manuscript preparation; Longsheng Lu and Hongguan Zhu helped perform the 
analysis with constructive discussions; and Yong Tang contributed to the conception of the study. Funding This work is sponsored by the Key Research and Development Project of Guangdong Province (2020B090926004) and Science and Technology Planning Project of Guangdong Province, China (2015B020238004).

Data availability The datasets used or analysed during the current study are available from the corresponding author on reasonable request.

\section{Compliance with ethical standards}

Conflict of interest The authors declare that they have no conflict of interest.

Ethics approval Not applicable

Consent to participate Not applicable

Consent for publication The manuscript is approved by all authors for publication; all the authors listed have approved the manuscript that is enclosed.

Code availability Not applicable

\section{References}

1. Kukulka DJ, Smith R (2014) Heat transfer evaluation of an enhanced heat transfer tube bundle. Energy 75: 97-103. https://doi.org/10.1016/j.energy.2014.04.113

2. Gorgy E, Eckels S (2019) Convective boiling of R-123 on enhanced-tube bundles. Int J Heat Mass Tran 134:752-767. https://doi.org/ 10.1016/j.ijheatmasstransfer.2019.01.061

3. Chen HP, Mo HJ, Wan ZP, Huang SF, Wang XW, Zhu HG (2020) Thermal performance of a boiling and condensation enhanced heat transfer tube-stepped lattice finned tube. Appl Therm Eng 173: 115227. https://doi.org/10.1016/j.applthermaleng.2020.115227

4. Chen J, Li W (2018) Local flow boiling heat transfer characteristics in three-dimensional enhanced tubes. Int J Heat Mass Tran 121:1021-1032.

https://doi.org/10.1016/j.ijheatmasstransfer.2018.01.065

5. Xu H, Dai YL, Cao HH, Liu JL, Zhang L, Xu MJ et al (2018) Tubes with coated and sintered porous surface for highly efficient heat exchangers. Front Chem Sci Eng 12(3):367-375. https://doi.org/10.1007/s11705-018-1703-1

6. Zeng Y, Xu H, Hou F, Dai Y, Liu J (2010)Property Studies on the Flame-Sprayed Type 
Surface Porous Tubes (in Chinese). Chemical Machinery 37(2):141-144.

http://en.cnki.com.cn/Article_en/CJFDTotal-HGJX201002002.htm

7. Lu LS, Tang Y, Yuan D, Deng DX (2011) Groove deformation analysis of a single plough on inner copper tube. J Mater Process Tech 211(11):1669-1677.

https://doi.org/10.1016/j.jmatprotec.2011.05.007

8. Pu H, Ding GL, Hu HT, Gao YF (2010) Effect of salt spray corrosion on air-side hydrophilicity and thermal-hydraulic performance of copper-fin heat exchangers. Heat Mass Transfer 46(8-9): 859-867. https://doi.org/10.1007/s00231-010-0634-2

9. Tang Y, Chi Y, Chen JC, Deng XX, Liu L, Liu XK et al (2007) Experimental study of oilfilled high-speed spin forming micro-groove fin-inside tubes. Int J Mach Tool Manu 47(78): 1059-1068. https://doi.org/ 10.1016/j.ijmachtools.2006.10.001

10. Kuboki T, Ishikawa M, Kajikawa S, Murata M (2018) An extrusion method of tube with spiral inner fins by utilizing generation of spiral outer fins grooves. Cirp Ann-Manuf Techn 67(1):305-308. https://doi.org/10.1016/j.cirp.2018.04.023

11. Wan ZP, Wang XW, Tang Y (2015) Heat Transfer Performance of an Edge-Shaped Finned Tube. Heat Transfer Eng 36(6): 574-581. https://doi.org/ 10.1080/01457632.2014.939527

12. Pham QV, Choi KI, Oh JT, Cho H (2019) Flow condensing heat transfer of R410A, R22, and R32 inside a micro-fin tube. Exp Heat Transfer, 32(2): 102-115. https://doi.org/10.1080/08916152.2018.1485783

13. Chen JX, Li W (2018) Local convective condensation heat transfer in horizontal doublelayer three-dimensional dimple-grooved tubes. Int J Heat Mass Tran 127: 810-820. https://doi.org/10.1016/j.ijheatmasstransfer.2018.07.131

14. Gu YH, Liao Q, Cheng M, Ding YD, Zhu X (2020) Condensation heat transfer characteristics of moist air outside a three-dimensional finned tube. Int J Heat Mass Tran 158: 119983. https://doi.org/10.1016/j.ijheatmasstransfer.2020.119983

15. Lee JM, Lee SW, Kim YK, Jo WH, Lee CJ, Kim BM (2016) Extrusion of AA 3003 Micro Condenser Tube with Multi-Hole and Thin Wall Section Using Porthole Die. Int J Pr Eng Man-GT 3(3): 239-245. https://doi.org/10.1007/s40684-016-0031-5 
16. Song M, Li YT (2007) Shrink Fit Technology of the Casing Fin Tubes (in Chinese). Chemical Machinery, 34(3): 159-161. http://en.cnki.com.cn/Article_en/CJFDTotalHGJX200703011.htm

17. Gujre VS, Anand R (2020) Machine learning algorithms for failure prediction and yield improvement during electric resistance welded tube manufacturing. J Exp Theor Artif In 32(4): 601-622. https://doi.org/ 10.1080/0952813x.2019.1653995

18. Stolecki M, Bijok H, Kowal L, Adamiec J (2015) Laser Welding of Finned Tubes Made of Austenitic Steels. Arch Metall Mater 60(3): 1807-1811. https://doi.org/10.1515/amm-20150309

19. Chen QQ, Liu J, Han JT (2010) Simulation of finned tube rolling under different technologies (in Chinese). Journal of Plasticity Engineering 17(1): 115-118. https://doi.org/10.3969/j.issn.1007-2012.2010.01.025

20. Guo Y, Huang LW, Li DY, Wan ZP (2011) Rolling Process of Ribs with Triangular Cross Section on Surface of Copper Tube. Key Eng Mater 467-469: 212-216. https://doi.org/10.4028/www.scientific.net/KEM.467-469.212

21. Tang Y, Lu LS, Pan MQ, Liu XK, Liu XQ (2006) Formation mechanism of external finned tubes by extrusion-plough method. T Nonferr Metal Soc 16(S2): 283-S288.

22. Wei X, Bin W, Yong T, Ye BY (2003) On chopping-extrusion of integral-fin copper tubes. J Mater Process Tech 138(1-3): 385-389. https://doi.org/10.1016/S0924-0136(03)00103-1

23. Wan ZP, Tang Y (2010) Production of integral serrated outside finned tube using a combined method of rolling and wedging/extruding. Int $\mathrm{J}$ Mach Tool Manu 50(5): 487-490. https://doi.org/10.1016/j.ijmachtools.2010.02.005

24. Unger S, Beyer M, Szalinski L, Hampel U (2020) Thermal and flow performance of tilted oval tubes with novel fin designs. Int J Heat Mass Tran 153: 119621. https://doi.org/10.1016/j.ijheatmasstransfer.2020.119621 
Figures
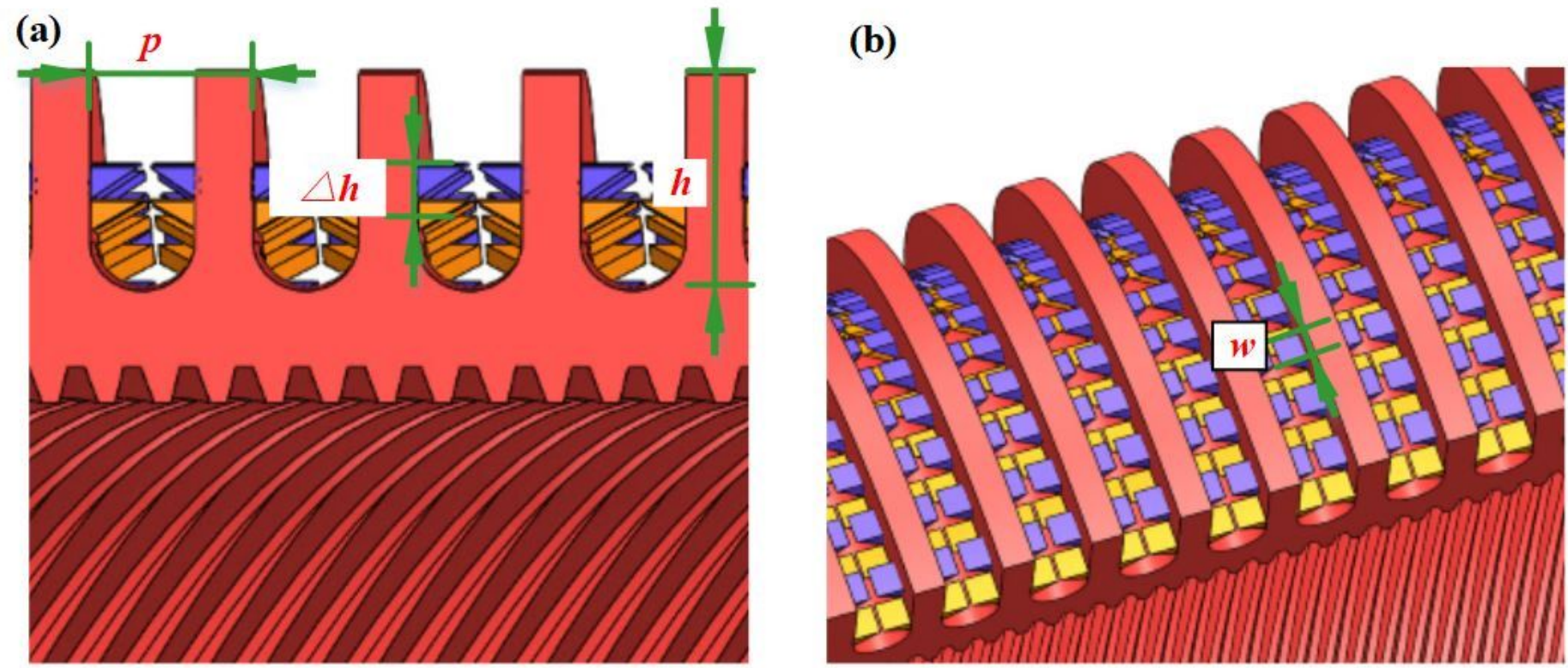

Figure 1

Schematic diagram of the SLFT: (a) longitudinal section view (b) top view

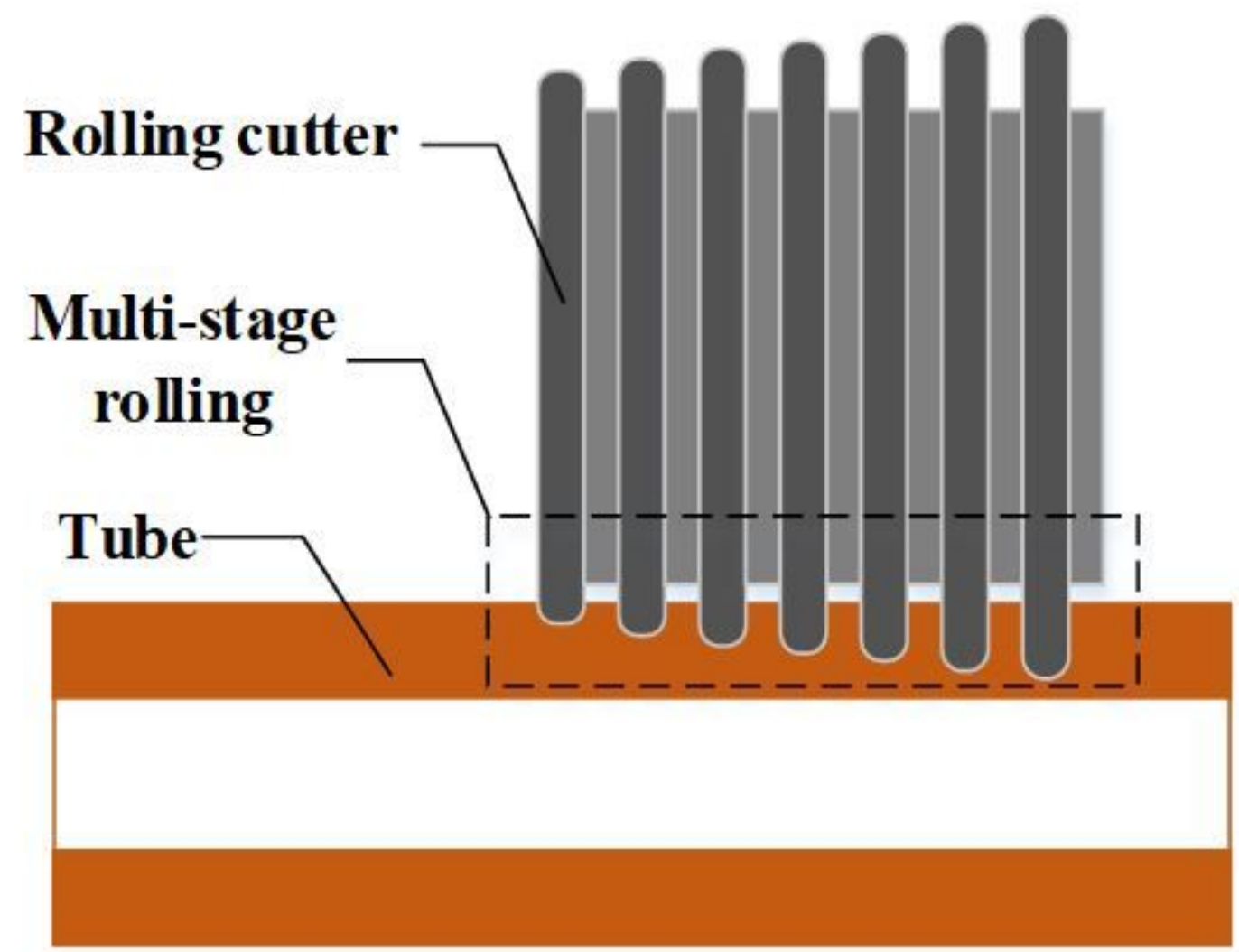


Figure 2

Multi-stage rolling of 2D helical fins

(a)

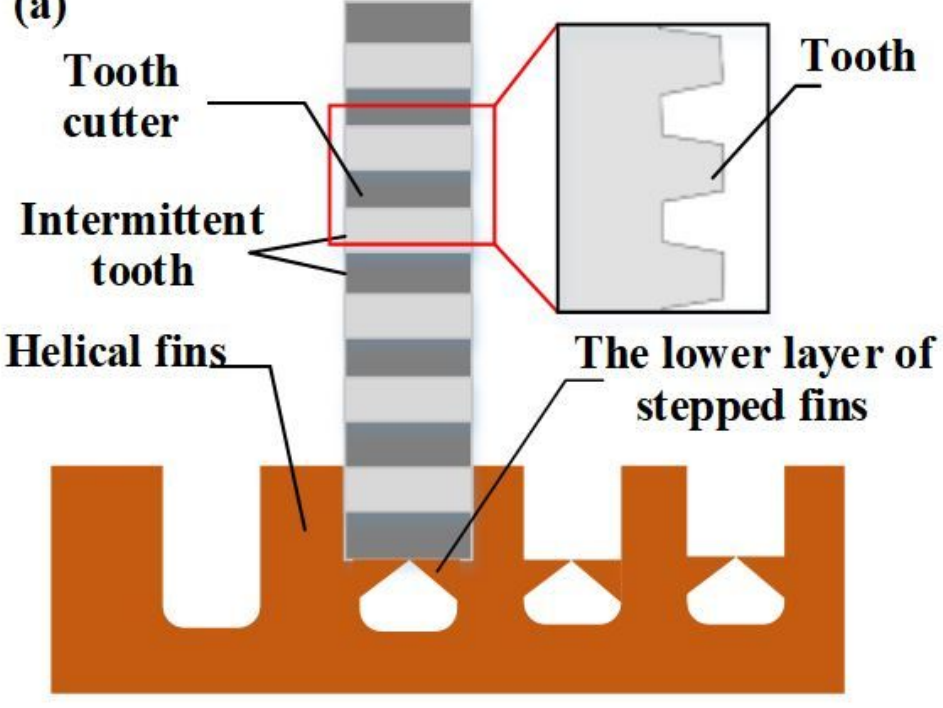

(b)

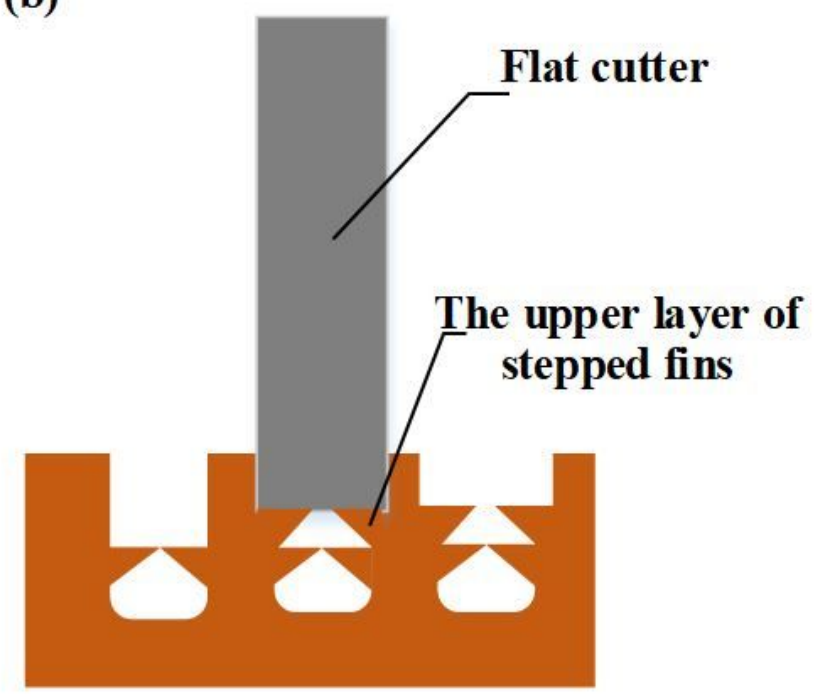

Figure 3

Forming method of stepped fins: (a) the first layer of stepped fin; (b) the second layer of stepped fin 


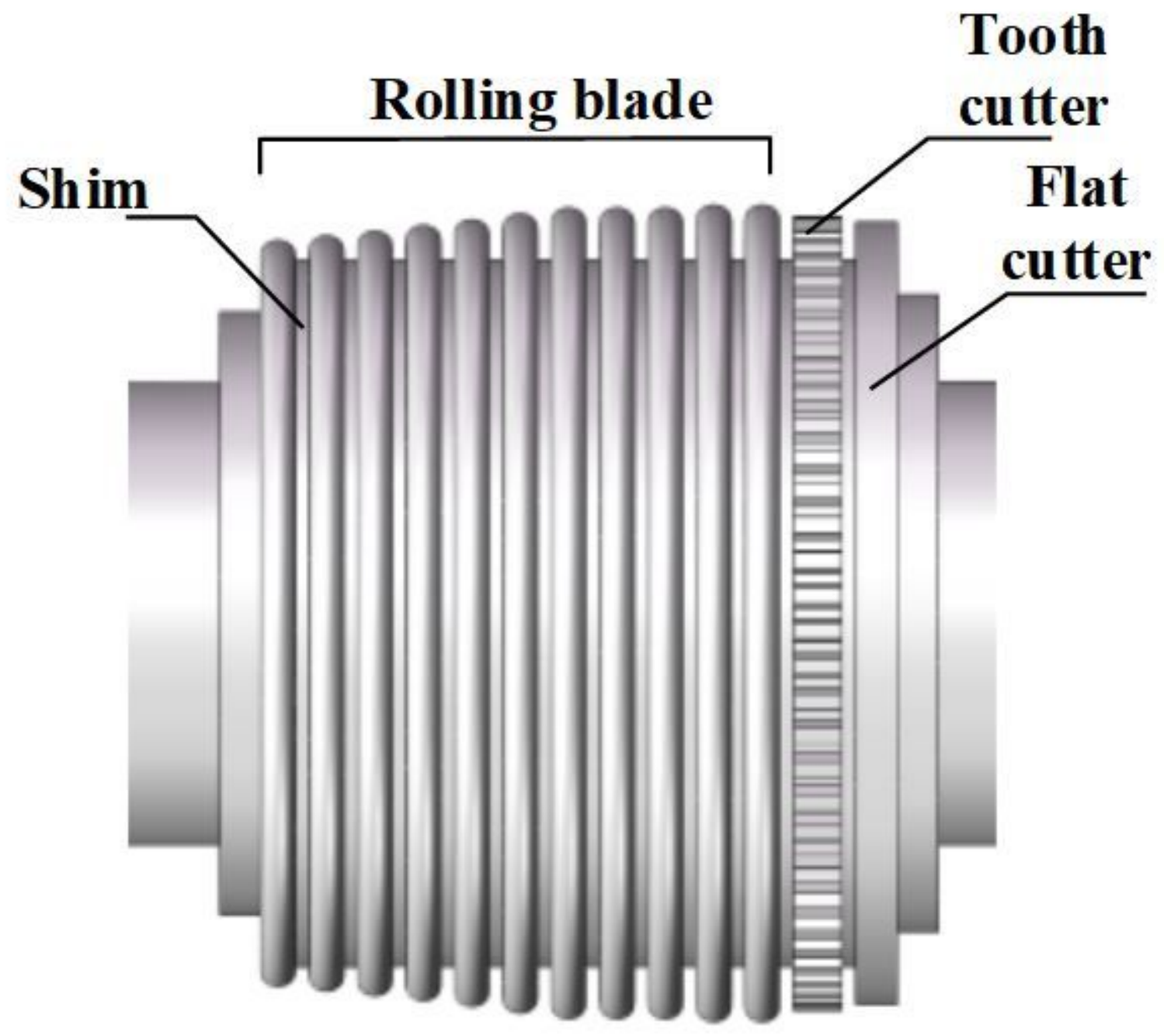

Figure 4

Schematic diagram of combined rolling-cutting tool 

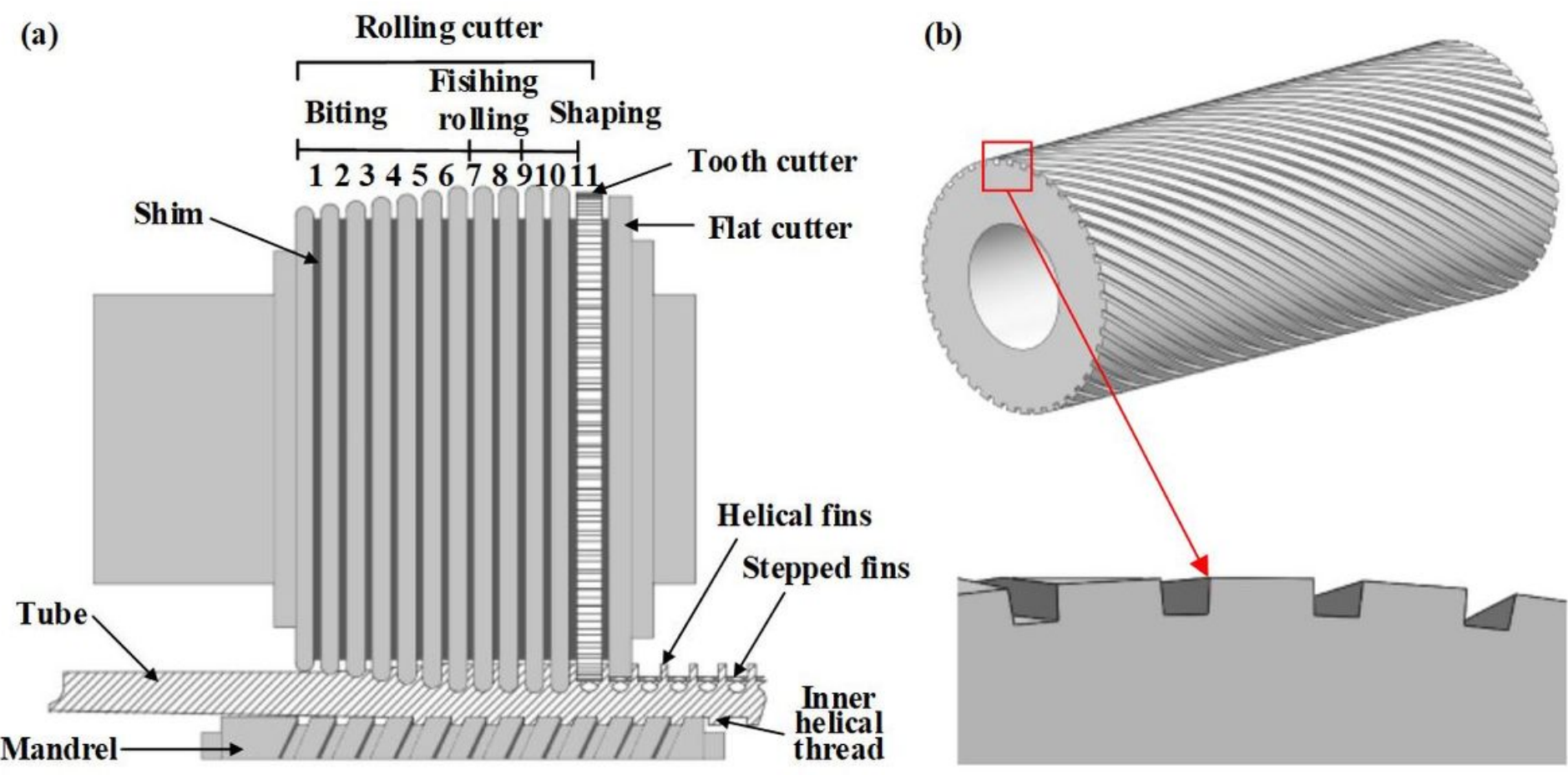

Figure 5

(a) schematic diagram of cooperative manufacturing of SLFT (b) configuration of the threaded mandrel

(a) Rolling-cutting

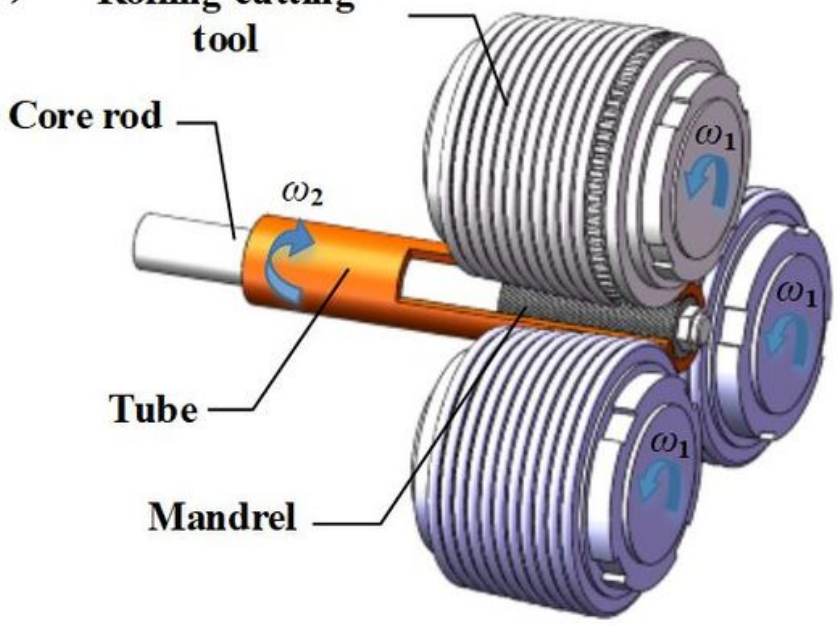

(b)

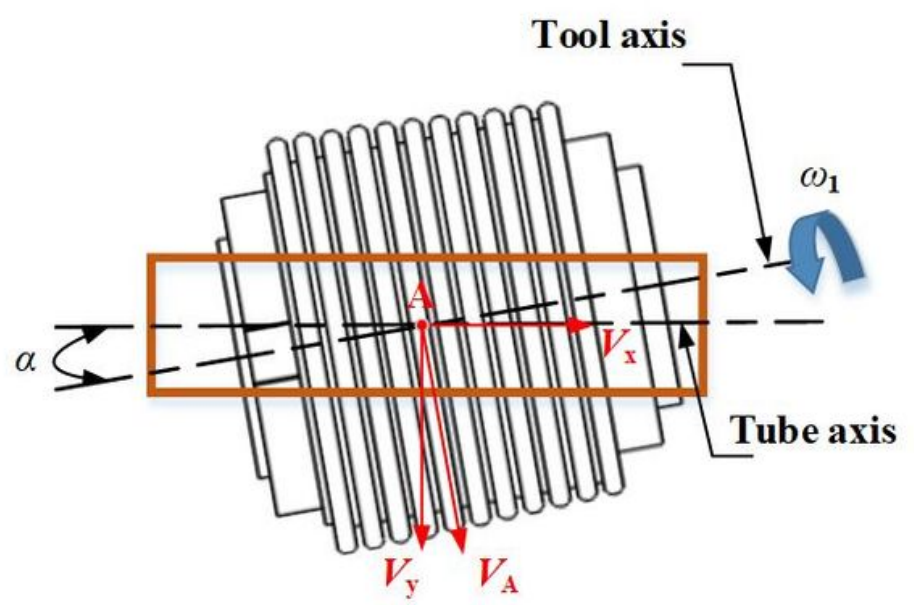

Figure 6

(a) Rolling-cutting-extruding forming of SLFT, (b) Schematic diagram of three-roller skew-rolling 


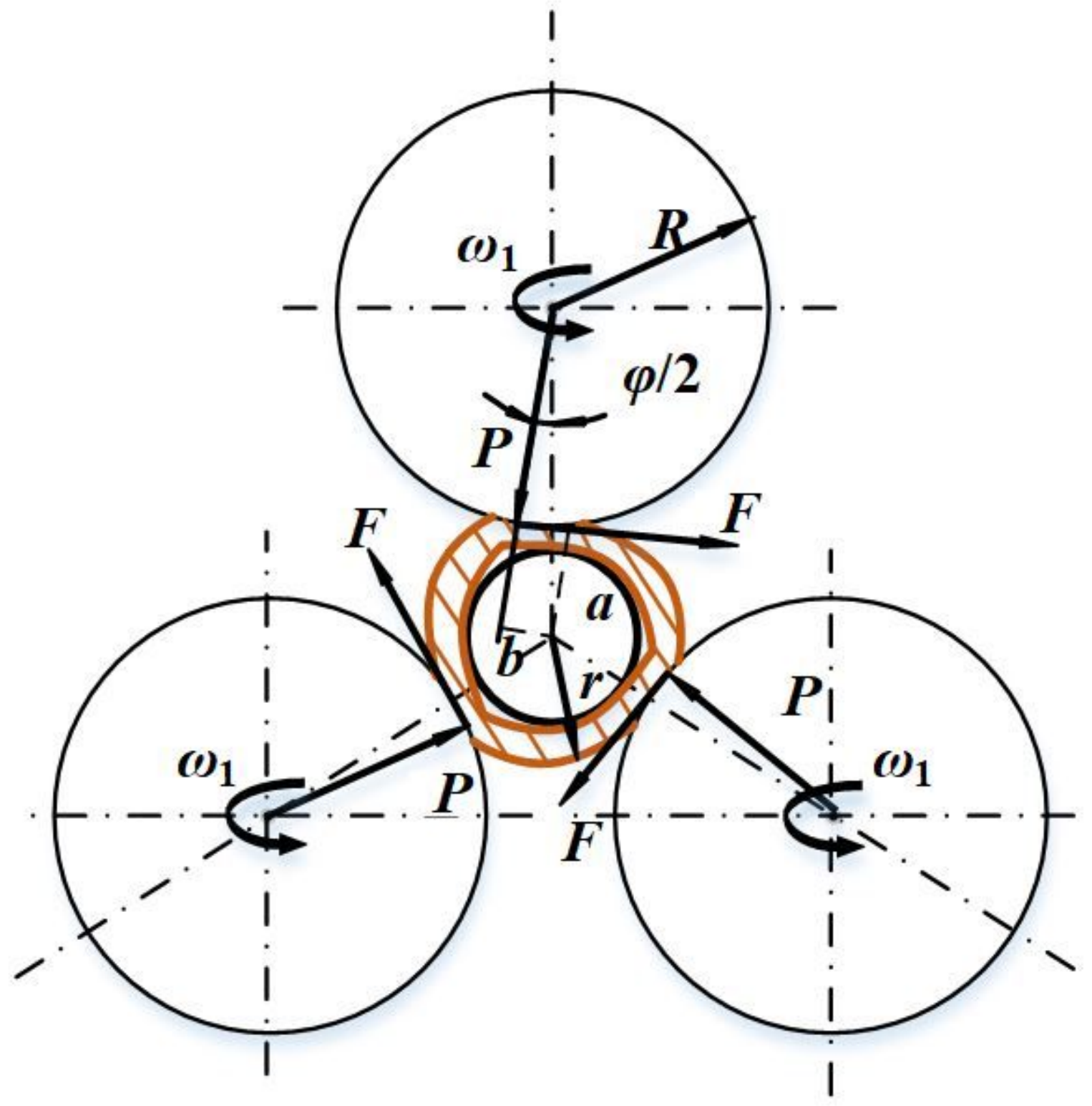

Figure 7

Schematic diagram of forces imposed on the tube 


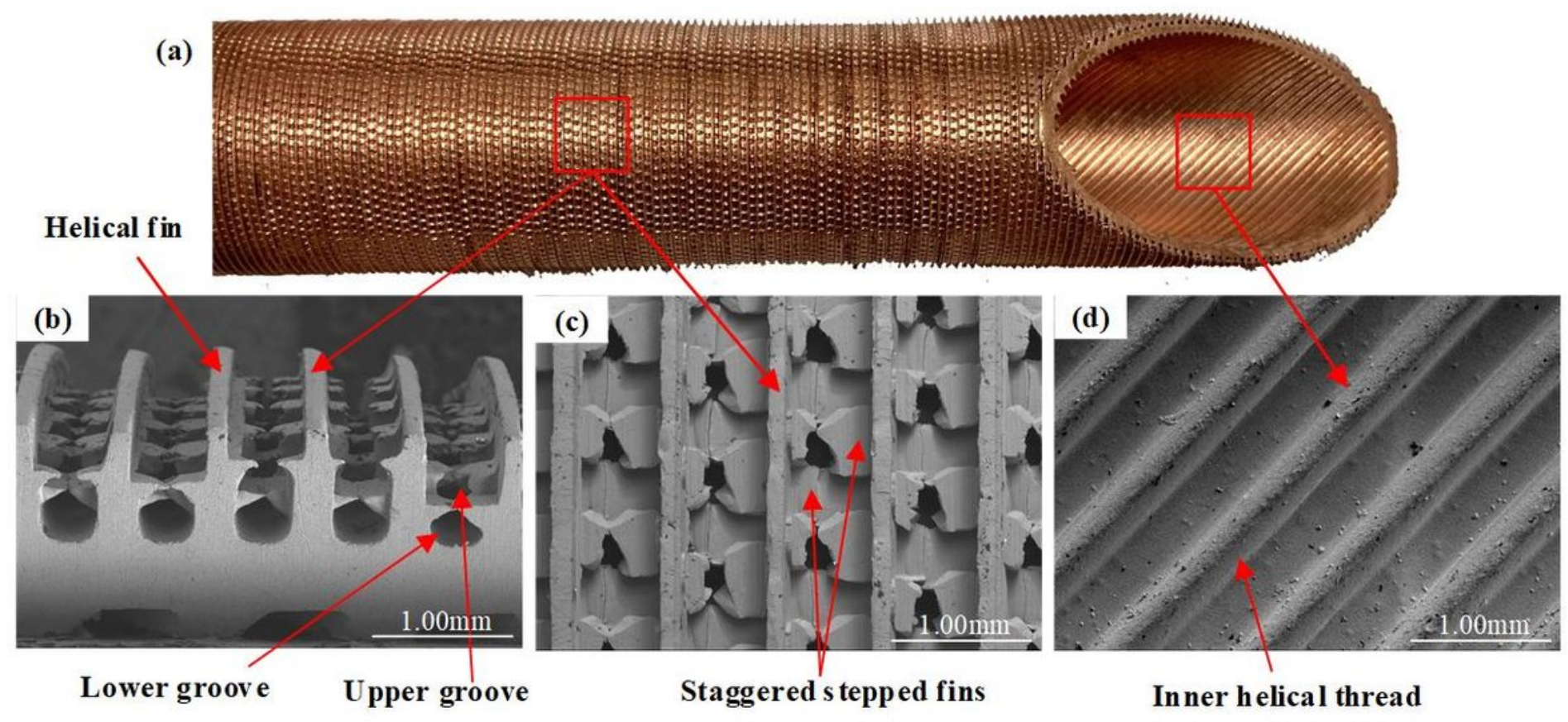

Figure 8

Appearance and characteristics of the SLFT: (a) appearance, (b) outer helical fins and (c) stepped lattice fins, (d) inner helical threads 


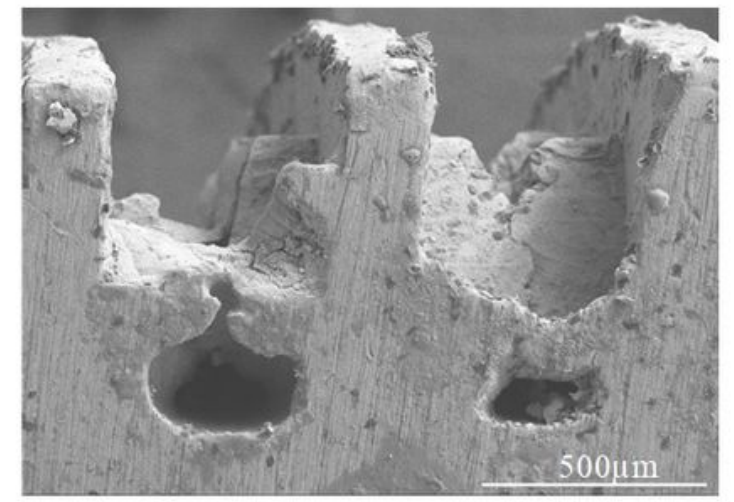

(a) Longitudinal section view

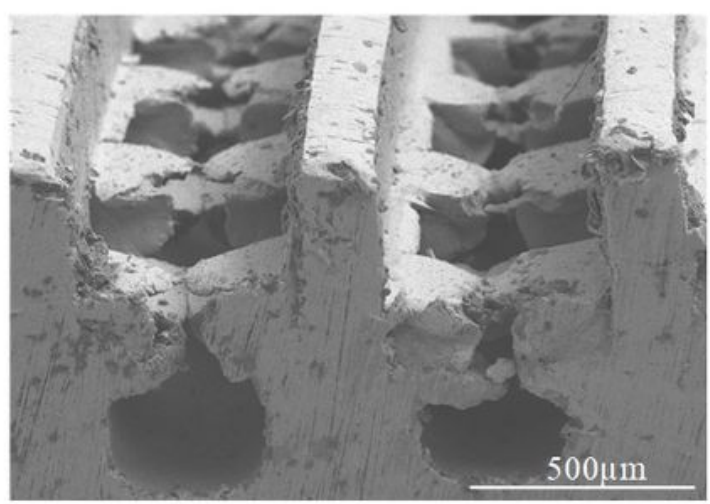

(c) Longitudinal section view

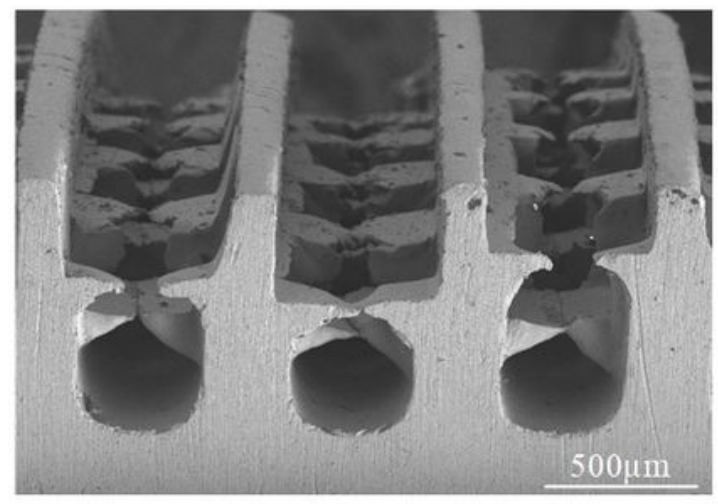

(e) Longit udinal section view

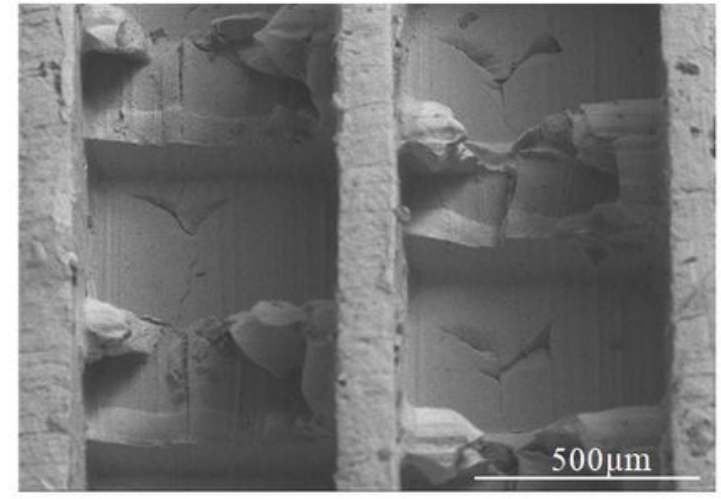

(b)Top view

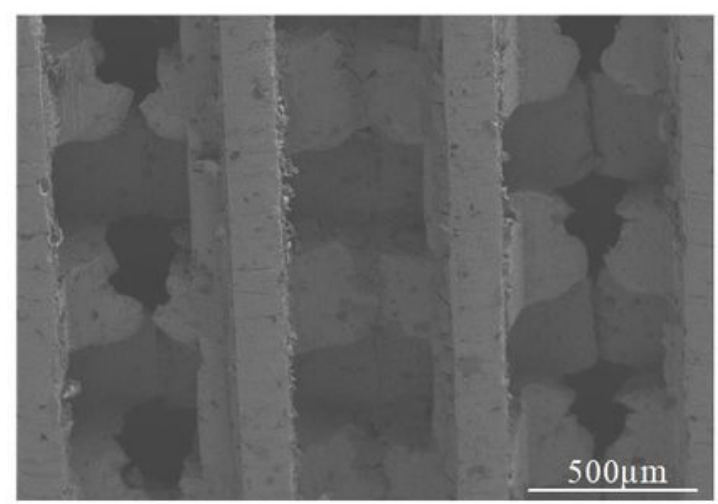

(d)Top view

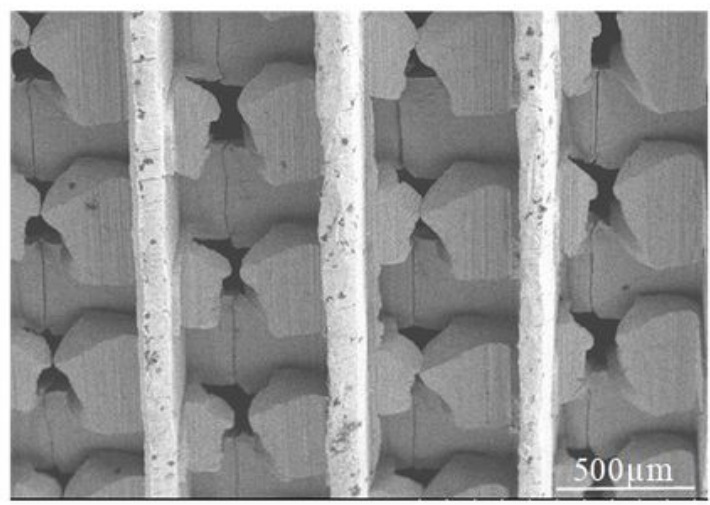

(f)T op view

\section{Figure 9}

Morphologies of the SLFT machined at rolling speed of: (a-b) 337r/min, (c-d) $235 \mathrm{r} / \mathrm{min}$, (e-f) $173 \mathrm{r} / \mathrm{min}$ 

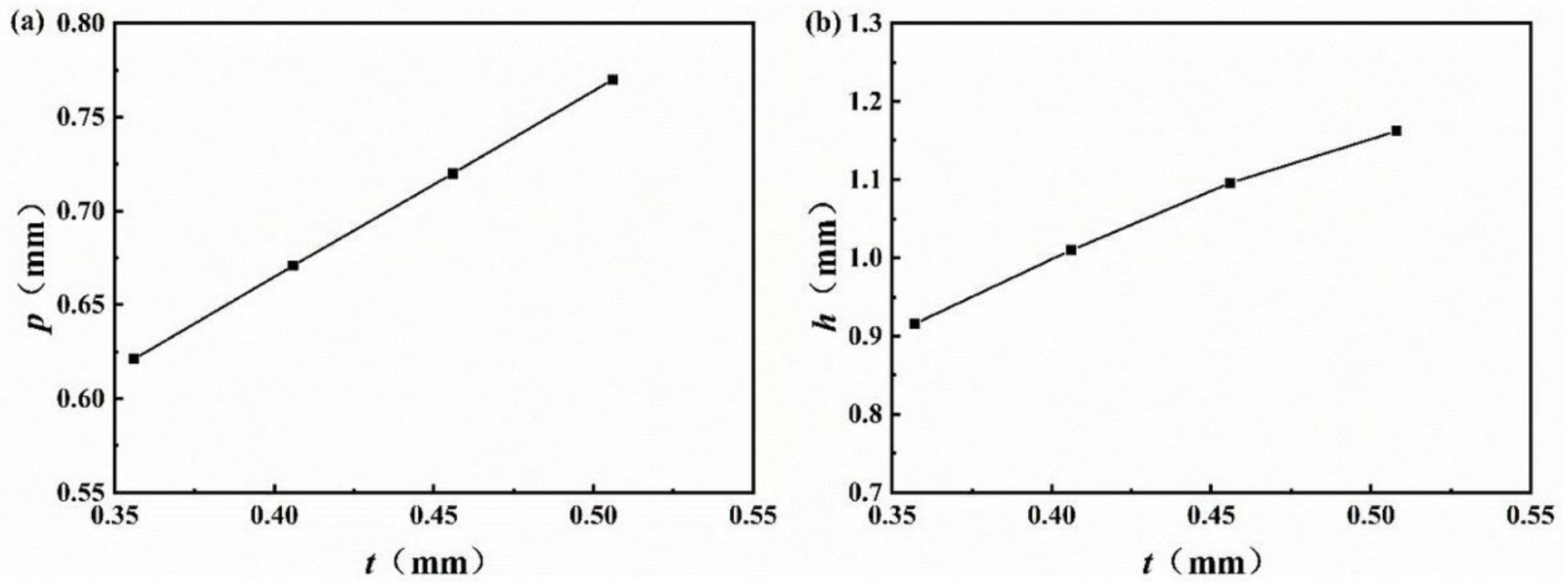

Figure 10

Pitch and height of 2D helical fins vs. the thickness of rolling blade: (a) pitch, (b) height difference of two layers of stepped fins with the difference in radius of the tooth cutter and flat cutter
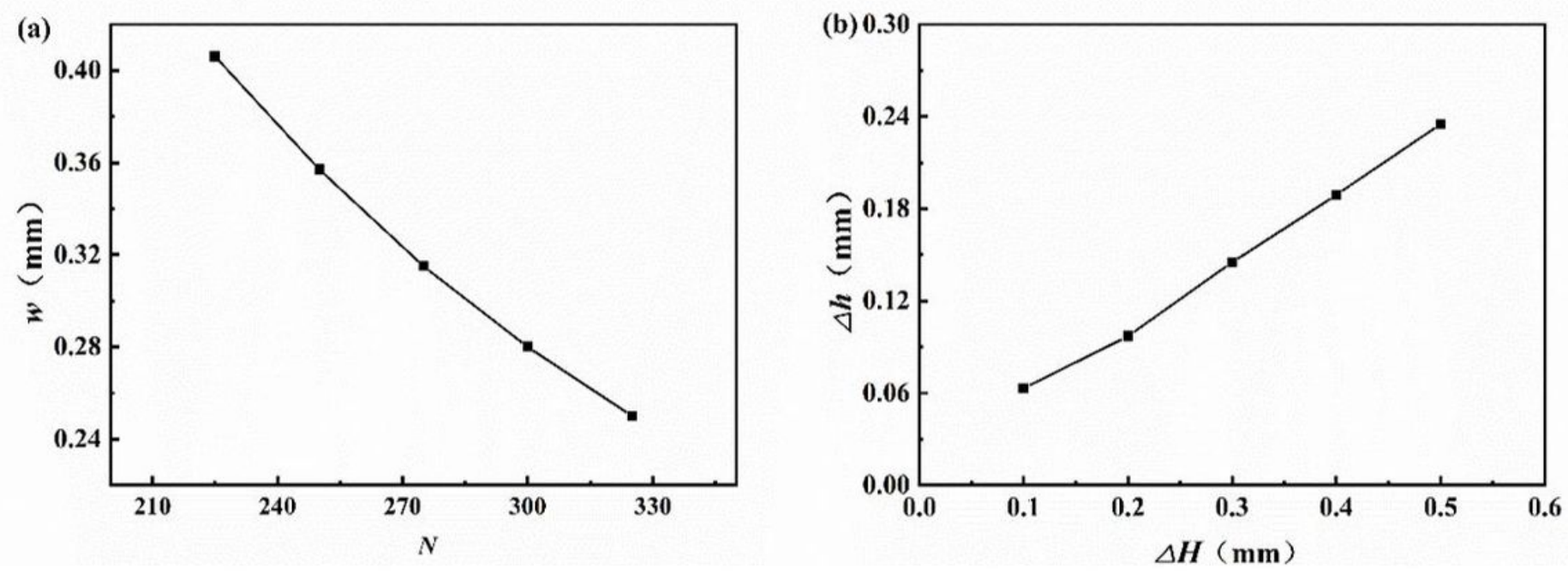

Figure 11

Variation trend of: (a) fin width varies with the number of teeth of the tooth cutter, (b) height 